\title{
PERANAN PENGAJAR DALAM KOLABORASI PENYAMPAIAN MATERI PELATIHAN IT TERHADAP SISWA
}

\author{
Role of Teacher in Collaboration of IT Training for Students
}

\author{
M. Arief Soeleman ${ }^{1}$, Pulung Nurtantio A ${ }^{2}$, Pujiono ${ }^{3}$, Noor Ageng Setiyanto ${ }^{4}$ \\ Email: arief22208@gmail.com ${ }^{1}$, pulung@ research.dinus.ac.id ${ }^{2}$, pujiono@dsn.dinus.ac.id ${ }^{3}$, \\ noorageng@dsn.dinus.ac.id ${ }^{4}$ \\ 1,2,3,4Fakultas Ilmu Komputer Universitas Dian Nuswantoro
}

\begin{abstract}
Abstrak
Siswa-siswi asuh dari Lembaga Amil Zakat Universitas Dian Nuswantoro, merupakan lembaga zakat yang dibentuk oleh karyawan muslim Universitas Dian Nuswantoro yang bertujuan memberikan bantuan uang sekolah setiap bulan untuk membayar biaya sekolah bagi siswa siswi sekolah menengah pertama dan sekolah menengah atas di kota Semarang yang tidak mampu untuk tetap bisa menyelesaikan sekolahnya. Motivasi bantuan sekolah untuk anak-anak binaan Lembaga Amil Zakat Udinus yang tidak mampu secara fiansial tetapi memiliki semangat dan kemampuan baik dalam akademik sehingga harus diberikan dukungan moril dan materiil agar tetap bisa meneruskan sekolahnya. Dengan memperhatikan kondisi diatas maka salah satu pendekatan yang perlu diambil adalah dengan peningkatan kualitas pengetahuan siswa siswi penerima LAZ agar tidak gagap terhadap teknologi atau tidak memiliki kemampuan dasar dalam menguasai dunia teknologi informasi. Sebagai seorang pelajar menggunakan teknologi informasi merupakan hal yang sangat minim, hal ini dikarenakan ketidak mampuan mereka memiliki peralatan teknologi informasi yang baik seperti komputer, laptop atau alat digital mobile. Disamping hal tersebut disekolah mereka masing-masing belum tentu mendapat pengetahuan teknologi informasi yang cukup karena tidak bersekolah ditempat yang baik fasilitasnya.
\end{abstract}

Kunci : pelatihan, teknologi informasi, siswa-siswi binaan

\section{PENDAHULUAN}

Saat ini anak asuh yang di kelola dalam Lembaga Amil Zakat Udinus mencapai lebih dari 40 siswa, hal ini tentunya perlu mendapat perhatian lebih intens agar mereka memiliki bekal yang lebih baik untuk menghadapi tantangan jaman ke depan. Setiap minggu anak-anak mendapat siraman rohani yang bertujuan untuk meningkatkan pemahaman dalam agamanya.

Akan tetapi bekal pengetahuan agama untuk ke depan masih belum cukup untuk meningkatkan pengetahuan dan ketrampilan bagi siswa siswi dalam menghadapi era teknologi yang semakin berkembang sangat cepat. Anak-anak harus memiliki ketrampilan lebih disamping pengetahuan agama yang diperoleh sebagai kegatan mentoring. Banyak siswa-siswi yang belum bisa mengelola keahliaan IT seperti pengetahuan internet, mengelola e-mail, membuat blog dan web site sederhana bagi siswa masing-masing.

Melihat kondisi tersebut diatas maka salah satu langkah yang perlu diambil adalah dengan peningkatan kualitas pengetahuan siswa siswi penerima LAZ agar tidak gagap terhadap teknologi atau tidak memiliki skill dasar dalam menguasai dunia IT. Sebagai seorang siswa-siswi menggunakan teknologi IT merupakan hal yang sangat minim, hal ini dikarenakan ketidak mampuan mereka memiliki peralatan IT yang baik seperti komputer, laptop atau alat digital mobile. Disamping hal tersebut disekolah mereka masing-masing belum tentu mendapat pengetahuan IT yang cukup karena tidak bersekolah ditempat yang baik fasilitas belajarnya. 
Dengan peningkatan kualitas sumber daya manusia bagi siswa-siswi penerima zakat diharapkan dapat berpengaruh pada daya saing individu itu sendiri. Sehingga mereka akan lebih percaya diri dalam bersaing diera global, disamping mereka bisa memulai belajar lebih dini tentang IT sehingga akan memiliki ide-ide kreatif dalam membekali pengetahuan yang tidak diperoleh secara langsung disekolah masing-masing.

Adapun langkah yang diambil adalah memberikan keterampilan tambahan pada mereka yang berusia produktif khususnya pengetahuan IT. Salah satu keterampilan yang akan diberikan pada masyarakat adalah keterampilan komputer (IPTEK). Dengan bekal keterampilan komputer diharapkan dapat mampu bersaing untuk mendapatkan pengetahuan yang lebih baik.

Strategi pelatihan dalam penyampaian materi kepada siswa-siswi sebagai bagian dari beberapa faktor yang berpengaruh terhadap pencapaian keberhasilan penyerapan materi bagi peserta pelatihan. Dalam hal ini metode pembelajaran dalam pelatihan untuk penyampaian materi telah terjadi perkembangan yang cukup pesat seiring dengan perkembangan teknologi informasi. Sebagai bagian dari pemanfaatan teknologi informasi, penting sekali memilih pendekatan yang tepat dalam penyampaian materi pelatihan kepada siswa-siswi yang berbeda tingkat kemampuan dan pemahaman dalam bidang teknologi informasi.

Adanya perkembangan konsep daam strategi pembelajaran khususnya dalam penyampaian pelatihan dari teacher-centered ke learner-centered mendorong pemberi materi menggunakan pendekatan yang tepat sehingga capaian dari proses dapat diserap oleh peserta pelatihan.

Salah satu pendekatan dalam pembelajaran adalah penerapan e-learning, merupakan bagian yang banyak diadopsi oleh dunia pendidikan, sehingga semakin banyak yang telah menerapkan konsep tersebut. Dari hasil kajian telah disimpulkan bahwa e-Learning sangat membantu dalam menyelesaikan masalah pendididkan di banyak negara maju, di Indonesia dengan perkembanagn teknologi informasi dan dengan UU Sistem Pendidikan Nasional yang telah mengizinkan diterapkannya alat bantu pembelajaran elektronik (Undang-undang Sisdiknas, 2003). Akan tetapi model pembelajaran e-learning ini lebih tepat dilakukan untuk proses yang bersifat jangka panjang.

\section{TINJAUAN PUSTAKA}

Belajar dilihat dari sudut pandang pendekatan kognitivisme, merupakan perubahan tentang persepsi dan pemahaman. Adanya terjadi suatu perubahan persepsi dan pemahaman tidak identik dalam bentuk perubahan perilaku yang dapat diobservasi. Pendekatan ini disimpulkan adanya setiap orang yang telah mempunyai pengalaman dan pengetahuan di dalam dirinya, hal ini tertata dalam bentuk struktur kognitif.

Pada pendekatan lain, bahwa pengetahuan dibangun dalam diri individu melalui proses interaksi yang saling terkait dengan lingkungan. Proses ini tidak diskontinue, terpisah-pisah dan melalui proses yang mengalir, bersambung-sambung, menyeluruh. Ibarat seseorang yang memaikan musik, ia tidak memahami not-not balok yang terpampang di partitur sebagai informasi yang saling lepas berdiri sendiri, tapi sebagai kesatuan yang secara utuh masuk ke pikiran dan perasaannya.

Pada pendekatan kognitif merupakan pendekatan yang cenderung kepada psikologi dibanding teori belajar, dalam penerapannya proses pembelajaran tidaklah mudah. Disamping itu pendekatan ini dianggap lebih sulit diterapkan secara murni karena tidaklah mungkin memahami "struktur kognitif" yang ada dalam benak setiap siswa. Ditahapan lanjut (advanced), seringkali tidak mudah untuk memahami dan mengidentifikasi pengetahuan yang sudah ada dalam benak siswa, sehingga antara pengetahuan dan pengalaman yang dimiliki siswa sudah terlalu majemuk untuk dikenali secara tuntas, apalagi hanya dengan menggunakan beberapa pre test (Carla Limongelli, et.al, 2009).

\section{METODE PENELITIAN}

Kolaborasi yang ditentukan oleh American Heritage Dictionary adalah "bekerja untuk bekerja bersama-sama dengan orang lain atau bersama-sama terutama dalam upaya intelektual. "Memang, literatur pembelajaran kolaboratif menunjukkan bahwa pembelajaran kolaboratif adalah, pertama dan terutama, latihan intelektual sosial yang berkaitan dengan penciptaan pengetahuan baru, di mana masalah atau tugas diajukan, dan solusi atau solusi dicari (Brody, Bruffee, 1995). Pembelajaran kolaboratif adalah 
didasarkan pada konstruktivisme sosial (Bruner, Dewey, 1916; Piaget, 1973; Vygotsky, 1978), dan berkaitan dengan menciptakan pengetahuan baru; terhadap tujuan ini, guru berfungsi sebagai fasilitator (Ornstein \& Hunkins, 1998) atau membimbing (Dewey, 1916) ke proses sosial penemuan. Dengan demikian, pembelajaran kolaboratif berkaitan dengan menumbuhkan siswa independensi, suasana perbedaan pendapat, kurangnya struktur kelompok, dan gratis pertukaran ide. Dalam pembelajaran kolaboratif, kelompok akan berusaha menjawab a pertanyaan, atau menghasilkan solusi untuk masalah; Namun, tidak ada yang bersamaan tujuan bahwa setiap anggota kelompok akan belajar dari pengalaman. Pembelajaran kolaboratif dapat dianggap berwawasan ke luar, tidak terstruktur proses kelompok di mana tujuan utama kelompok adalah untuk menghasilkan, melalui interaksi kreatif, solusi atau solusi terbaik - yaitu, konstruksi pengetahuan (Brody, 1995).

\section{HASIL DAN PEMBAHASAN}

Pada dua model kooperatif dan kolaboratif keduanya adalah proses kelompok kecil, kooperatif dan pembelajaran kolaboratif adalah proses yang berbeda secara substantif dengan tujuan yang berbeda. Model kooperatif adalah proses yang sangat terstruktur yang dicirikan oleh tingkat individu yang tinggi akuntabilitas, interdependensi anggota positif, dan keterampilan sosial pengembangan. Interdependensi positif adalah pusat pengembangan lingkungan pembelajaran kooperatif dan, kemudian, untuk komitmen keberhasilan masing-masing dan setiap anggota kelompok: ini adalah jantung dari model belajar kooperatif (Johnson et al., 1998).

Sebaliknya, pembelajaran kolaboratif tidak berbagi elemen kooperatif juga tidak berbagi tujuan umum pembelajaran kooperatif. Model belajar kolaboratif adalah proses kelompok kecil yang tidak terstruktur yang berkembang pada kemandirian, pemikiran bebas, dan perbedaan pendapat. Tujuan dari pembelajaran kolaboratif proses adalah membuat anggota kelompok memikirkan dan memecahkan masalah- masalah yang mungkin tidak memiliki jawaban spesifik, atau beberapa solusi. Pendeknya, tujuan pembelajaran kolaboratif adalah untuk menciptakan pengetahuan baru melalui konteks sosial. Meskipun anggota kelompok diharapkan bekerja sama, tidak ada komitmen kepada anggota kelompok yang masingmasing akan belajar dan menjadi sukses sebagai hasil dari proses. Pembelajaran kolaboratif adalah, pada dasarnya, seorang intelektual proses dalam kerangka sosial laissez-faire.

Tabel 1. Perbedaan Model Cooperative dan Kolaborasi

\begin{tabular}{|l|c|l|}
\hline \multicolumn{1}{|c|}{ Karakteristik } & Model Cooperative & \multicolumn{1}{c|}{ Model Kolaborasi } \\
\hline Pengetahuan & Dasar / Fondasi & Non Dasar : Sosial artifak \\
\hline Orientasi & Instruksi terstruktur & Konstruksi sosial \\
\hline Proses & Orientasi Capaian & Aksi dalam pelatihan \\
\hline Struktur Grup & $\begin{array}{c}\text { Tinggi / Positif } \\
\text { /Interdepence }\end{array}$ & Rendah / Individual \\
\hline Peranan Siswa & Kooperatif / Menerima & Independen / dissident \\
\hline
\end{tabular}




\begin{tabular}{|l|c|l|}
\hline Tujuan & $\begin{array}{c}\text { Membangun kemampuan } \\
\text { sosial dan pembelajaran } \\
\text { untuk semua anggota }\end{array}$ & $\begin{array}{l}\text { Membangun pengetahuan melalui } \\
\text { percakapan untuk penyelesaian masalah }\end{array}$ \\
\hline
\end{tabular}

Sebelum melakukan proses pelatihan siswa-siswa diberikan suatu model tanya jawab yang bertujuan untuk menggali tingkat pemahaman dari masing-masing terhadap materi yang akan disampaikan. Adapun beberapa pertanyaan digali tentang email meliputi cara membuat dan pengelolaan, kemudian pemahaman tentang blog, cara membuat dan mengelola serta pembuatan website sederhana.

Dari beberapa pertanyaan awal banyak siswa siswi yang hanya mengetahui sekilas tentang mengelola email, kemudian kaitannya email dengan pembauatan blog pribadi serta hampir 99 persen siswa belum pernah belajar membuat website pribadi. Dengan demikian maka dilakukan pelatihan mulai dari awal mengenal email sampai dengan membuat, kemudian membuat blog pribadi menggunakan blogspot serta mendesain website dengan menggunakan bahasa html.

Ternyata siswa-siswi sangat antusias dalam mengikuti proses pelatihan, hal ini ditunjukkan dari proses interaktif tanya jawab dan pendampingan dari asisten terhadap beberapa masalah yang ditemui ketika mendesain blog dan web. Dengan melakukan pengamatan dan pendampingan secara intensif siswa-siswi LAZ ternyata memiliki kemampuan yang baik dalam menyerap materi yang disampaikan oleh instruktur dan asisten yang melakukan pendampingan.

Ada beberapa hal yang menjadi kendala dalam proses pelatihan ini. Beberapa siswa masih ada yang belum mengenal peralatan komputer secara baik, hal ini disebabkan karena keterbatasan latar belakang dari asal sekolah yang dijadikan tempat belajar siswa tidak pernah memberikan pengenalan peralatan komputer. Kemudian kendala yang lain adalah pemahaman beberapa istilah yang menggunakan bahasa asing ketika membuat email, website juga ikut berperan dalam kecepatan menerima materi yang diajarkan.

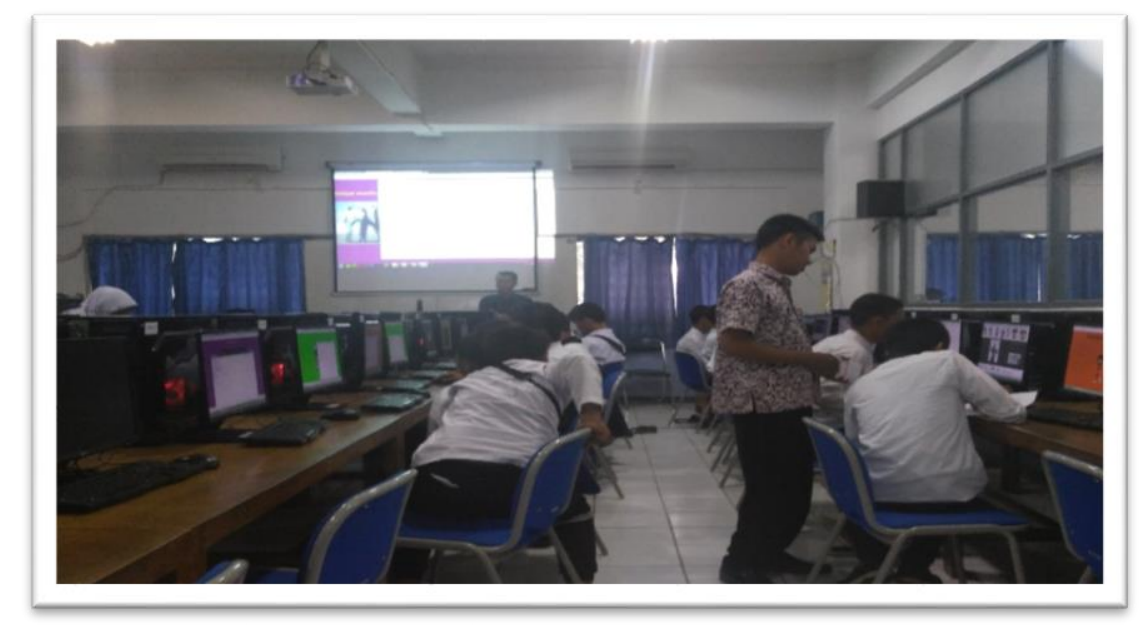

Gambar 1. Pendampingan oleh Asisten 


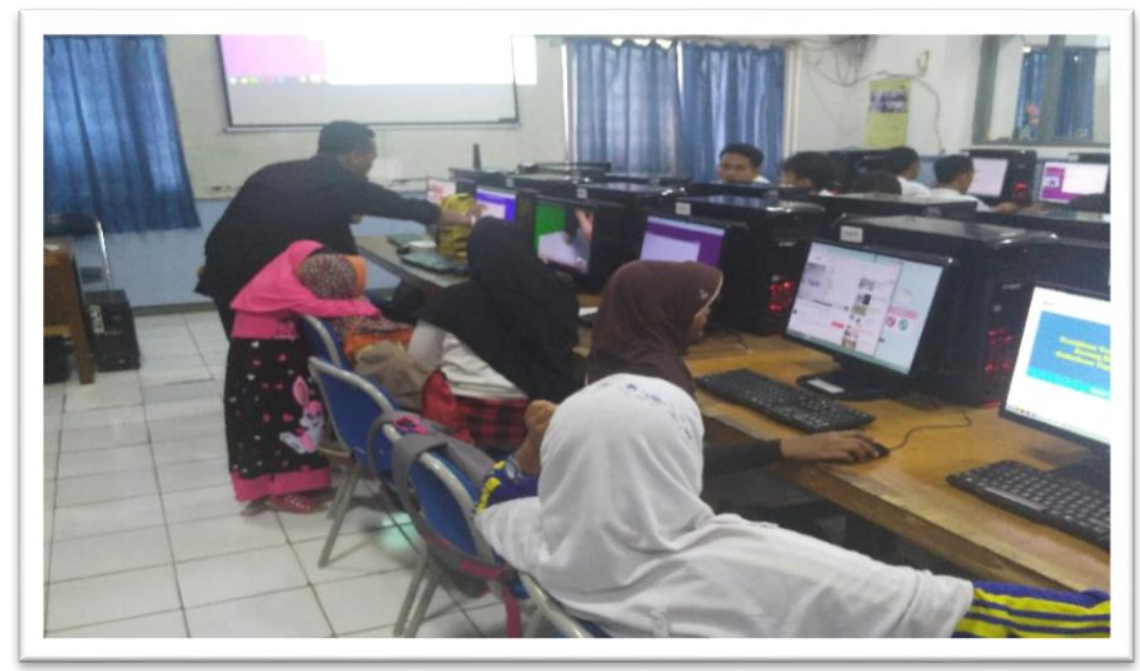

Gambar 2. Instruktur memberi pengarahan secara interaktif

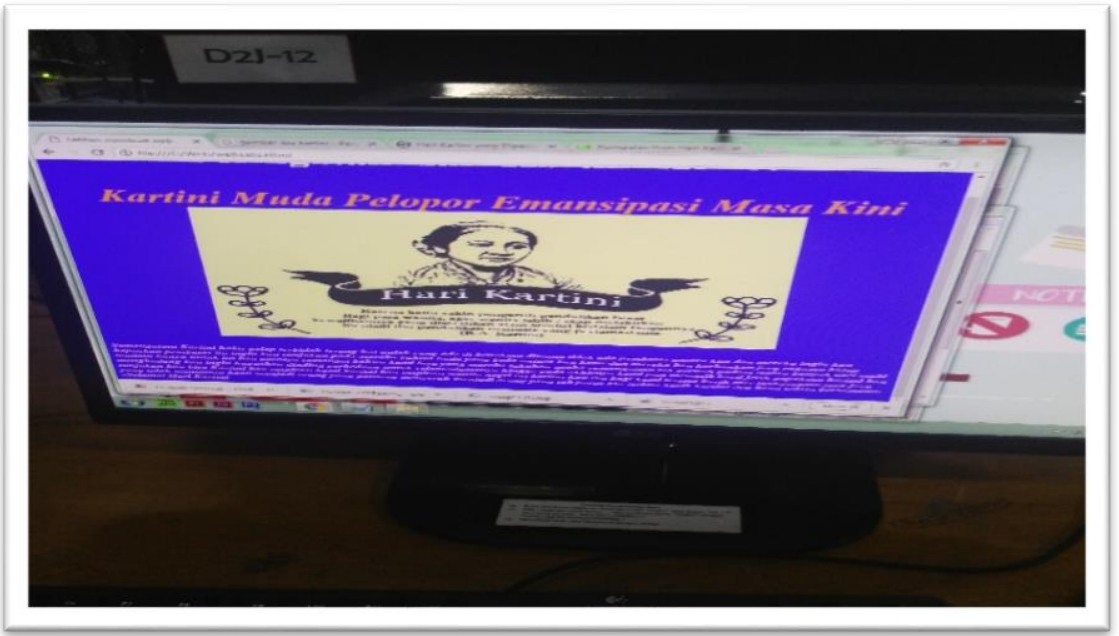

Gambar 3. Salah satu hasil website sederhana dengan HTML

\section{EVALUASI}

Evaluasi merupakan tahapan penting dalam melakukan proses pelatihan khususnya transfer pengetahuan dibidang teknologi informasi. Tahapan evaluasi yang dilakukan terdiri dari memberikan beberapa penugasan untuk melakukan perubahan pada beberapa desain web, blog, dimana penugasan ini untuk menguji daya ingat dan kreatifitas dari siswa-siswi dalam menguasai sedikit materi yang telah diajarkan. Meskipun dilakukan evaluasi tetapi tidak memberikan justifikasi nilai terhadap peserta pelatihan.

\section{KESIMPULAN}

Dari kegiatan Ipteks bagi Masyarakat, khususnya siswa siswi penerima bantuan pendidikan oleh Lembaga Amil Zakat Universitas Dian Nuswantoro dapat di simpulkan beberapa hal diantaranya bahwa :

a. Kegiatan pelatihan IT bagi siswa - siswi sangat diperlukan dalam rangka meningkatkan kemampuan tambahan bagi siswa agar memiliki skill dan pengetahuan lebih. Pada dasarnya siswa-siswi sudah mendapat pengenalan komputer ketika disekolah, akan 
tetapi pengetahuan pembuatan blog, email dan web pribadi belum pernah mereka dapatkan selama belajar di bangku sekolah;

b. Bahwa untuk keberhasilan kegiatan tersebut sangat bergantung terhadap pemateri dalam menyampaikan bahan pelatihan. Hal ini lebih disebabkan bahwa tidak meratanya kemampuan siswa dalam satu kelas pelatihan;

c. Asisten dalam kegiatan perlu lebih aktif agar siswa lebih cepat berinteraksi terhadap materi yang disampaikan oleh pemateri.

\section{DAFTAR PUSTAKA}

Assaf, L. C. (2005). Staying connected: Student teachers' perceptions of computer- mediated discussions. The Teacher Educator, 40(4), 221-235.

Brody, C. M. (1995). Collaboration or cooperative learning? Complimentary practices for instructional reform. The Journal of Staff, Program \& Organizational Development, 12(3), 133-143.

Brookfield, S., \& Preskill, S. (1999). Discussion as a way of teaching: Tools and techniques for democratic classrooms. San Francisco: Jossey-Bass.

Bruffee, K. A. (1995, January/February). Sharing our toys: Cooperative learning versus collaborative learning. Change, pp. 12-18.

Bruner, J. S. (1996). The culture of education. Cambridge, MA: Harvard University Press.

Cannon-Bowers, J. A., Salas, E., \& Converse, S. A. (1990). Cognitive psychology and team training: Shared mental models in complex systems.

Carlsmith, K. C., \& Cooper, J. (2002). A persuasive example of cooperative learning. Teaching of Psychology, 29, 132-135.

Carla Limongelli, Filippo Sciarrone, Marcom Temperini, and Giulia Vaste, Adaptive Learning with the LS-Plan System: A Field Evaluation, IEEE Transactions on Learning Technologies, Vol. 2, No.3, July-September 2009.

Deatz, R. C., \& Campbell, C. H. (2001). Applications of cognitive principles in distributed computer-based training (Research Product 20-01-03).

Alexandria, VA: U.S. Army Research Institute for the Social and Behavioral Sciences.

Dewey, J. (1916). Democracy and education. New York: The Free Press

Undang-undang No.20 Tahun 2003 tentang Sistem Pendidikan Nasional

The 2006 Nonprofit and Association E-Learning Survey represents a continuation of the work begun in 2004 with the first comprehensive survey of e-learning. www.isophinstitute.com/shared/asset. Diunduh 20 Agustus 2008

Iva'n Marti'nes-Ortiz, Jose'-Luis Sierra, and Baltasar Ferna'ndez-Manjo'n, Authoring and Reenginering of IMS Learning Design Units of Learning, , Senior Member, IEEE Transacsion, July-September 2009.

Nikos Tsianos, Zacharias Lekkas, Panagiotis Germanakos, Costas Mourlas, and George Samaras, An Experimental Assessment of the Use of Cognitive and Affective Factors in Adaptive Educational Hypermedia, Evaluation, IEEE Transactions on Learning Technologies, Vol. 2, No. 3, July-September 2009.

Yuh-Ming Cheng, Lih-Syhang Chen, Hui-Chuang, Sheng-Feng Weng, Yong-Guo Chen, and Chyi-Her Lin , Building a General Purpose Pedagogical Agent in a Web-Based Multimedia Clinical Simulation System for Medical Education, , Evaluation, IEEE Transactions on Learning Technologies Vol. 2, No. 3 JULY-September 2009 